\title{
Morphological, haemodynamic, and clinical variables as predictors for management of isolated ventricular septal defect
}

\author{
Freek van den Heuvel, Teun Timmers, John Hess
}

\begin{abstract}
Objective-To assess the predictive impact of morphological, haemodynamic, and clinical variables in the management of patients with isolated ventricular septal defect.

Design-Retrospective analysis of variables by a sophisticated database management system.

Patients and methods-263 consecutive patients with isolated ventricular septal defect diagnosed by echocardiography. The morphological type and haemodynamic character of the ventricular septal defect was characterised in each patient. In addition, variables were introduced to represent the need for diuretics, growth, and potential delay in growth. In 43 patients $(16 \cdot 3 \%)$ the ventricular septal defect was closed surgically; 220 patients (83.7\%) were managed conservatively and spontaneous closure of the ventricular septal defect occurred in 65 (29.5\%). There were no deaths.

Results-All patients managed surgically had non-restrictive defects and were operated on during the first year of life. A few patients with non-restrictive defects were managed conservatively. The two groups differed significantly only with respect to mean growth delay $(0.65)(0.27)$ $v 0.9(0.21), P<0.001)$. Only the morphology of the ventricular septal defect significantly $(P<0.001)$ influenced the probability of closure.

Conclusions-Findings imply that early surgical closure of ventricular septal defect is indicated in patients with nonrestrictive ventricular septal defect and severe growth delay. Other patients should be managed conservatively. In these patients the morphological type of the defect determines the probability of spontaneous closure and provides an estimate of the period over which decrease in size or closure can be expected.
\end{abstract}

(Br Heart f 1995;73:49-52)

Keywords: management, predictors, ventricular septal defect.

Non-restrictive ventricular septal defect giving rise to cardiac failure is generally accepted as an indication for surgery. The timing of surgery, however, is still controversial, mainly because of the risks of developing pulmonary vascular obstructive disease and the probability of spontaneous closure of the defect. ${ }^{1-3}$ Other influences are local experience with early primary repair and the infrastructure for postoperative care. ${ }^{14}$

Only a minority of patients with isolated ventricular septal defect will ultimately require surgical intervention. Such defects tend to close spontaneously. In several studies the morphological type of the defects has been identified as the most important determinant of spontaneous closure. ${ }^{25}$ Although there is consensus on these qualitative aspects, quantitative insight into the probability of closure over time is generally lacking.

To gain more insight into the variables that determine the management of patients with isolated ventricular septal defect we studied retrospectively a series of 263 such patients. We identified variables that may have determined or influenced the observed treatment, and we assessed the natural course of ventricular septal defect in relation to its morphological type and size in patients who were managed conservatively.

\section{Patients and methods}

PATIENTS

We studied 263 consecutive patients born between 1 January 1989 and 1 September 1993 who were diagnosed as having an isolated ventricular septal defect at this hospital. Only patients with isolated ventricular septal defect or ventricular septal defect in combination with an open foramen ovale were included in the study. Patients with additional structural cardiac abnormalities were excluded. All cases were diagnosed by echocardiography. In some patients additional information obtained by cardiac catheterisation was available.

One hundred and twenty seven patients were girls and 136 boys. Mean age at diagnosis was 2.9 months (range 0 to 30 months). Mean duration of follow up was 15.5 months (range 1 month to $4 \cdot 3$ years).

All data were collected using a dedicated paediatric cardiology database management system based on a personal computer (RW Brower, unpublished data). Both diagnostic and management data were coded with an extensive classification system based on sequential analysis. ${ }^{6}$ 
CHARACTERISATION OF DEFECTS

Ventricular septal defects were classified as muscular ( $n=105)$, perimembranous $(n=$ 95), perimembranous with extension to either inlet or outlet parts of the interventricular septum $(n=36)$, or subarterial $(n=4)$. In 23 patients the ventricular septal defect was characterised as small with no other details. To measure the haemodynamic importance of the ventricular septal defect each defect was characterised as either restrictive or non-restrictive according to Doppler echocardiographic data or, when available, measurements obtained during diagnostic catheterisation. The pressure gradient across the ventricular septal defect was calculated from the maximum flow velocity across it according to a version of the Bernoulli equation; when it was less than $10 \mathrm{~mm} \mathrm{Hg}$ the ventricular septal defect was defined as nonrestrictive. To indicate growth retardation a variable was introduced to represent whether growth was below the third, between the third and 10 th, or above the 10th centile. Values were based on the patient's weight at clinics during the first 1.5 years of life, using standard growth curves. For patients who had surgery to close the defect values were based on measurements obtained during the period before the operation. In addition, a variable was introduced within the group of patients with non-restrictive ventricular septal defect to measure potential growth delay. This was done by calculating the ratio of the amount of growth observed over a period of time to the amount of growth expected over the same period determined from the 50th weight centile. Finally, the use of diuretics was taken as an indicator of a large left to right shunt to categorize the haemodynamic significance of the ventricular septal defect.

FOLLOW UP

Forty three patients were managed surgically (table 1). In 41 patients the ventricular septal defect was repaired with a patch, in one patient by direct suture and one patient with multiple ventricular septal defects by banding of the pulmonary artery. The defect was approached transatrially in all primary repairs. In 28 patients additional minor structural

Table 1 Comparison of variables to characterise ventricular septal defect in patients managed conservatively and surgically. Values are numbers (percentages) of patients

\begin{tabular}{|c|c|c|c|c|}
\hline Variable & Conservative $(n=220)$ & Surgery $(n=43)$ & Total & $P$ value ${ }^{*}$ \\
\hline \multicolumn{4}{|l|}{ Haemodynamics: } & \multirow[t]{2}{*}{$<0.001$} \\
\hline Non-restrictive & $12(5)$ & $43(100)$ & $\begin{array}{r}55 \\
208\end{array}$ & \\
\hline \multicolumn{4}{|l|}{ Morphology: } & \multirow[t]{6}{*}{$<0.001$} \\
\hline Muscular & $103(47)$ & $2(5)$ & 105 & \\
\hline Perimembranous & $74(34)$ & $21(49)$ & 95 & \\
\hline Perimembranous with & $20(9)$ & \multirow{3}{*}{$\begin{array}{c}16(37) \\
4(9)\end{array}$} & 36 & \\
\hline Subarterial & 0 & & $\begin{array}{r}50 \\
4\end{array}$ & \\
\hline \multirow{2}{*}{\multicolumn{4}{|c|}{$\begin{array}{l}\text { Unknown } \\
\text { Drug treatment: }\end{array}$}} & \\
\hline & & & & \multirow[t]{3}{*}{$<0.001$} \\
\hline Yes & $25(11)$ & $33(77)$ & 58 & \\
\hline \multicolumn{2}{|l|}{ Growth (centile): } & $10(23)$ & 205 & \\
\hline $\begin{array}{l}\text { Growth (centile): } \\
<10\end{array}$ & $46(21)$ & $27(63)$ & 73 & \multirow{3}{*}{$<0.001$} \\
\hline$\geqslant 10$ & $151(69)$ & $16(37)$ & 167 & \\
\hline Unknown & $23(10)$ & & 23 & \\
\hline
\end{tabular}

${ }^{\star}$ All $\chi^{2}$ tests. Values are based on comparison between conservatively and surgically managed patients for each variable separately. abnormalities were corrected: in 20 patients a patent foramen ovale was closed, in two patients a previously unknown secundum type atrial septal defect was closed, and in six patients a small ductus arteriosus was ligated. The mean age at surgery was 6.4 months (range 1 to 46 months). A trivial residual ventricular septal defect remained in five patients after surgery.

Two hundred and twenty patients were managed conservatively (table 1). Spontaneous closure was observed in 65 of them. The mean age at the time the ventricular septal defect was found to have closed was 16.6 months (range 1 to 46 months). At the end of the study the ventricular septal defect was still open in 155 patients, whose mean age was 19.5 months (range 0 to 53 months).

No patient died during follow up.

\section{STATISTICAL ANALYSIS}

Data are presented as means and ranges unless indicated otherwise. Tests of significance for the comparison of means were performed by the two sample $t$ test. For nominal data $\chi^{2}$ analysis was used. The Kaplan-Meier method of life table estimation was used to calculate the probability of spontaneous closure within the group of patients who were managed conservatively. The log rank test statistic for equality was used for the comparison of survival distributions based on a single variable. Logistic regression techniques were used to substantiate the influence of the different variables on outcome, in which case the Wald statistic was used for significance testing. In all statistical tests significance was defined as $P<0.05$.

\section{Results}

Table 1 compares data in the patients managed conservatively and surgically. All variables used to characterise the ventricular septal defect differed significantly in the two groups. All ventricular septal defects that were managed surgically were non-restrictive, and the majority of conservatively managed defects were restrictive. When the morphological characteristics were reviewed almost all of the 43 surgically managed defects were of the perimembranous (37 patients) and subarterial (four) type. Finally, both growth retardation and the need for supportive medical treatment were more prominent in the surgically managed group.

\section{CONSERVATIVE MANAGEMENT}

In 208 (95\%) of the 220 patients managed conservatively the ventricular septal defect was of the restrictive type; the 12 other patients initially had non-restrictive ventricular septal defect (table 1). Of all 65 spontaneous closures observed in the study, 62 were restrictive (table 2). Three spontaneous closures occurred in the 12 patients with nonrestrictive defects. Seven of the nine remaining patients showed a reduction in the size of the defect during follow up. No such reduction was seen in the two others, the decision 
Table 2 Comparison between ventricular septal defects that closed spontaneously and those that remained open in 220 conservatively treated patients. Values are numbers (percentages) of patients

\begin{tabular}{lllll}
\hline Variable & $\begin{array}{l}\text { Spontaneously closed } \\
(n=65)\end{array}$ & Open $(n=155)$ & Total & Pvalue* \\
\hline $\begin{array}{l}\text { Haemodynamics } \\
\text { Non-restrictive }\end{array}$ & $3(5)$ & $9(6)$ & 12 & NS \\
$\begin{array}{l}\text { Restrictive } \\
\text { Morphology: }\end{array}$ & $62(95)$ & $14694)$ & 208 & \\
$\quad$ Muscular & $43(66)$ & $60(39)$ & 103 & $<0.001$ \\
$\begin{array}{l}\text { Perimembranous } \\
\text { Perimembranous with }\end{array}$ & $11(17)$ & $63(41)$ & 74 & \\
$\quad$ extension & $2(3)$ & $18(12)$ & 20 & \\
Unkown & $9(14)$ & $14(9)$ & 23 & \\
\hline
\end{tabular}

${ }^{\star}$ All $\chi^{2}$ tests; NS, not significant.

to close the ventricular septal defect being made later. The intervention took place after completion of the study.

Only the morphology of the ventricular septal defect differed significantly between patients with spontaneous closures and those with persisting defects. Kaplan-Meier life table analysis estimated the probability of spontaneous closure over time, (figure). A significant difference $(P<0.001)$ was found between the curves for muscular and perimembranous (both with and without extension) ventricular septal defect. After about 1 year of age the probability that a muscular ventricular septal defect will be open is 0.72 (SE 0.048; 56 patients remaining). For perimembranous ventricular septal defect this probability is $0.92(0.031 ; 61$ remaining). In our study a probability of closure of 0.50 $(0.065 ; 17$ remaining) is observed at 2.3 years of age only for muscular ventricular septal defect.

\section{SURGICAL MANAGEMENT}

Review of the 43 patients who had surgery showed that 41 patients were operated on before the age of 1 year (mean age $5 \cdot 2$ months (range 2 to 12 months)). The remaining two patients were operated on at the age of 1.3 and 3.9 years, respectively. The reasons for these late interventions were stagnation of the

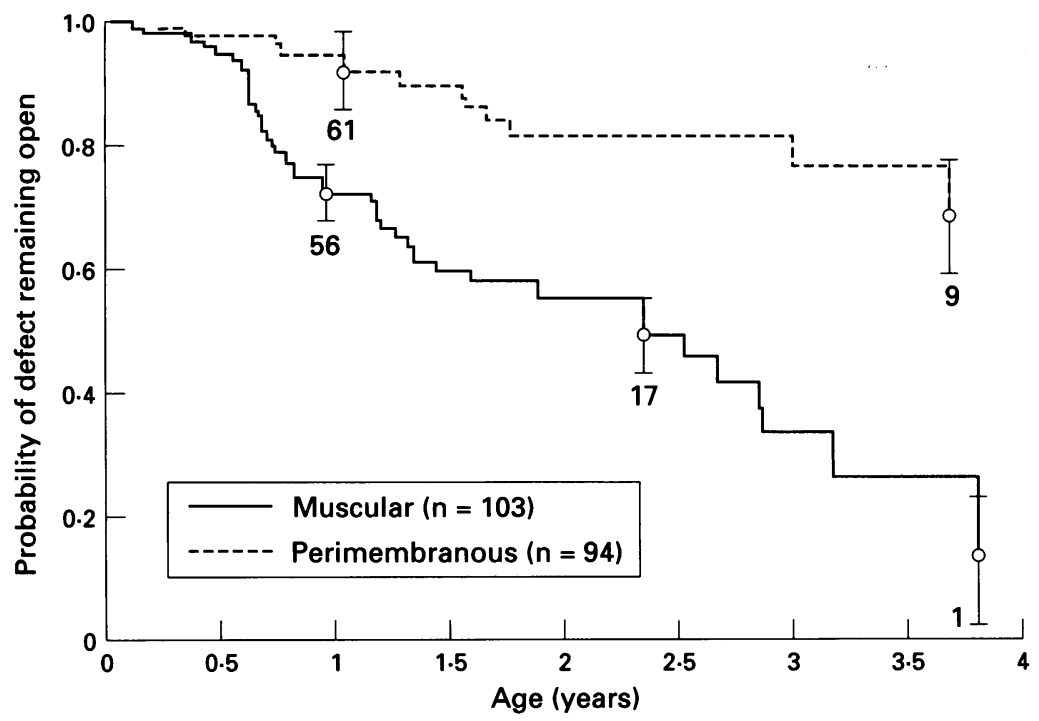

Kaplan-Meier survival curves estimating the probability that a ventricular septal defect will remain open during follow up in a group of 197 conservatively treated patients with either muscular or perimembranous defect. Vertical bars show the probability with $S E$ and numbers are remaining patients. initial reduction in the left to right shunt during follow up in one patient and a moderate left ventricular volume overload that was not well tolerated in a defect that had become restrictive before the age of 1 year in the other.

Table 1 shows that no patient with restrictive ventricular septal defect was operated on and that all patients managed surgically had non-restrictive defect. However, not all patients with initially non-restrictive ventricular septal defect were operated on. To determine the influence of the variables used to characterise ventricular septal defect on whether to operate or manage conservatively the two groups of patients with non-restrictive ventricular septal defect were compared. The surgically managed group showed significantly more growth delay than the conservatively managed group (0.65 (SD 0.27) v $0.9(0.21)$; $P<0.001)$. To determine which of the variables might discriminate between the two management groups a multivariate logistic model was calculated. The analysis is shown in table 3. The only variable significantly associated with increasing odds of operative management was growth of $60 \%$ or less of expected growth. No similar significant influence was found for the other variables.

\section{Discussion}

\section{SURGICAL VERSUS CONSERVATIVE}

MANAGEMENT

In our study surgical management within the first year of life is expected in one out of every six patients with isolated ventricular septal defect. All patients managed surgically had non-restrictive ventricular septal defect, but not all patients with such defects were managed surgically: a small number of patients with (initially) non-restrictive ventricular septal defect were managed conservatively. Among these patients the size of this defect was reduced and in three of the cases the defect closed spontaneously. These two groups were significantly different only with respect to growth rate (table 3 ). Patients with restrictive ventricular septal defect are not operated on within such a short period of time. When a restrictive ventricular septal defect persists over several years of follow up volume overload may be an indication for surgical closure.

\section{SPONTANEOUS CLOSURE}

Several studies have focused on spontaneous reduction or closure of ventricular septal defects and the influence of size and morphology in this process. ${ }^{5-10}$ Results vary considerably among these papers with respect to both incidence and influence of morphology and size. In most series the rate of closure was highest in the first year of life. Only Dickinson et al found a uniform rate of closure (3\% per year over the first 10 years of follow up) ${ }^{9}$ Moe et al found spontaneous closure in $45 \%$ of patients followed up from birth and in $22 \%$ of those who had been referred, but size did not influence closure. ${ }^{10}$ In another study $75 \%$ of the muscular ventricular septal defects closed spontaneously during the first year and $12 \%$ 
Table 3 Multivariate logistic model for outcome of patients with non-restrictive septal defect

\begin{tabular}{lll}
\hline Variable & $\beta(S E)$ & Odds ratio (significance) \\
\hline Drug treatment & $-0.236(0.860)$ & 0.790 (NS) \\
Morphology: & $-0.377(1.517)$ & 0.686 (NS) \\
$\quad$ Perimembranous (v muscular) & $0.944(1.619)$ & 2.571 (NS) \\
$\quad \begin{array}{l}\text { Perimembranous with extension or subarterial } \\
\text { (v muscular) }\end{array}$ & \\
Weight (centile): & $-0.016(0.897)$ & 0.984 (NS) \\
$\quad<3$ rd $(v>10$ th) & $-0.982(1.041)$ & $0.375(\mathrm{NS})$ \\
3rd-10th $(v>10$ th) & $2.599(1.172)$ & $13.447(0.01<\mathrm{p}<0.05)$ \\
Growth delay $(<60 \%$ of expected) &
\end{tabular}

^For each variable this figure represents the factor by which the odds of operative versus conservative management is multiplied when the variable is present.

showed a significant reduction in diameter. ${ }^{5}$ In most studies muscular ventricular septal defects predominate over perimembranous defects, except in the study by Moe et al. ${ }^{10}$

We found that the probability of spontaneous closure is determined by morphology rather than by the size of the defect. Actuarial analysis showed that the probability that a ventricular septal defect will close spontaneously during the first year of life is about 3.5 times higher for ventricular septal defects of the muscular type than for defects characterised as perimembranous. Subarterial ventricular septal defects do not spontaneously reduce in size. After the first year of life both types of defects continue to close spontaneously but at a lower rate.

\section{CONCLUSION}

The need for surgical management of isolated ventricular septal defect is mainly determined by the haemodynamic character of the ventricular septal defect. Patients born with non-restrictive defects have a high probability of needing surgery. Because early primary closure is now possible with both low mortality (in our series no patient died) and low morbidity ${ }^{112}$ delaying surgery is no longer indicated when patients present with overt growth delay or cardiac failure. Favourable improvement in postoperative growth after early surgical intervention as described by Weintraub et al supports this policy of early intervention. ${ }^{13}$ However, because spontaneous reduction in size or even closure is not influenced by the size of the defect conservative management may be indicated even for large ventricular septal defects, especially if the defect is in the muscular septum, provided that the clinical status of the patient permits a protracted treatment regimen.

We found that the morphology of the ventricular septal defect determines the probability of spontaneous reduction in size and provides an estimate of the period over which this reduction can be expected. Finally, we found that a sophisticated paediatric database management system facilitates clinical research over relatively short periods of follow up, leading to relevant data for decision making.

1 van Hare GF, Soffer LJ, Sivakoff MC, Liebman J. Twentyfive-year experience with ventricular septal defect in infants and children. Am Heart $\mathcal{f}$ 1987; 144:606-14.

2 Williams RG. Doppler color flow mapping and prediction of ventricular septal defect outcome [editorial]. $f \mathrm{Am}$ ooll Cardiol 1989;13:1119-21.

3 Kidd L, Driscoll DJ, Gersony WM, Hayes CJ, Keane JF O'Fallon WM, et al. Second natural history of congenital heart defects: results of treatment of patients with heart defects: results of treatment of patients with ventricular
I39-51.

4 Rizolli G, Blackstone EH, Kirklin JW, Pacifico AD Bargeron LM. Incremental risk factors in hospital mortality after repair of ventricular septal defect. $\mathcal{F}$ Thorac Cardiovasc Surg 1980;80:494.

5 Hornberger LK, Sahn DJ, Krabill KA, Sherman FS, Swensson RE, Pesonen E, et al. Elucidation of the natural history of ventricular septal defects by serial Doppler color flow mapping studies. $\mathcal{f} \mathrm{Am}$ Coll Cardio 1989;13:1111-8.

6 van den Heuvel F, Timmers T, van Mulligen EM, Hess J. Knowledge-based modeling for the classification and follow-up of patients with congenital heart disease. In: Lun KC, Degoulet P, Piemme TE, Rienhoff O, eds. Proceedings of the seventh world congress on medical informatics. Amsterdam: Elsevier, 1992:501-5.

7 Hoffman JE, Rudolph AM. The natural history of ventricular septal defects in infancy. Am $\mathcal{f}$ Cardiol 1965;16: 634-53.

8 Alpert BS, Cook DH, Varghese PJ, Rowe RD. Spontaneous closure of small ventricular septal defects: Spontaneous closure of small ventricular sep
ten-year follow-up. Pediatrics 1979;63:204-6.

9 Dickinson DF, Amold $R$, Wilkinson JL. Ventricular septal defect in children born in Liverpool, 1960 to 1969: evaluation of natural course and surgical implications in an unselected population. Br Heart $\mathcal{f} 1981 ; 46: 47-54$.

10 Moe DG, Guntheroth WG. Spontaneous closure of uncomplicated ventricular septal defect. $\mathrm{Am} \quad \mathcal{F}$ Cardiol 1987;60:674-8.

11 Otterstad JE, Erikssen J, Froysaker T, Simonson S. Longterm results after operative treatment of isolated ventricular septal defect in adolescents and adults. Acta Med Scand 1986;708(suppl): $1-39$.

12 Hardin JT, Muskett AD, Canter CE, Martin TC, Spray TL. Primary surgical closure of large ventricular septal defects in small children. Ann Thorac Surg 1992;53: 397-401.

13 Weintraub RG, Menahem S. Early surgical closure of a large ventricular septal defect: influence on long-term growth. 7 Am Coll Cardiol 1991;18:552-8. 